\title{
Effect of Visfatin Level and Other Biochemical Parameters in Iraqi Children and Adolescents with Obesity
}

\author{
Mithal R. Alkubaisi ${ }^{1}$, Raghd A. Y. Alkhader ${ }^{2}$, Noor Thair Tahir ${ }^{3 *}$, Abdilya R. \\ ALAbdaly $^{4}$, Luay Asaad Mahmood ${ }^{5}$ \\ ${ }^{1,5}$ College of Medicine, University of Anbar, Ramadi, Iraq. \\ ${ }^{2}$ Chemistry and Biochemistry Department, College of Medicine, Mustansiriyah University, Baghdad - Iraq. \\ ${ }^{3}$ National Diabetes Centre, Mustansiriyah University, Baghdad - Iraq. \\ ${ }^{4}$ Facullty of Medicine, University of Jordan, Amman, Jordan. \\ *Corresponding author.Email: noor9ttahir@gmail.com
}

\begin{abstract}
In this study, the aim was to evaluate visfatin level in Iraqi children and adolescents with obesity, as well as to study the association of serum visfatin level with different biochemical variables. Ninety participants were included. Participants' ages ranged between ( 5 and 18) years. Sixty obese children and adolescents (obese group) compared to thirty children and adolescents (control group). Serum visfatin concentrations have been measured by ELISA. Results: There was a highly significant increase in serum visfatin levels in obese group compare to control group. In addition, there was a highly significant increase in serum visfatin level in obese adolescents in comparison with obese children. A significant positive association was seen between serum visfatin level verses weight, waist circumference, HOMAIR and LDL-C in both obese children and obese adolescents. Moreover, positive correlations were detected between serum visfatin level verses FBS and TG in both obese children and obese adolescents. Conclusion: serum levels of visfatin are elevated in obese group. These findings suggest that visfatin may possibly play a role in the pathophysiology of obesity in children, who are at risk for a broad range of future diseases, such as type II diabetes and heart disease.
\end{abstract}

Keywords: Visfatin, Adolescents, Children, Obesity.

\section{INTRODUCTION}

Obesity is usually characterized by the excessive accumulation of adipocytes and linked to various disorders, for example type II diabetes and insulin resistance [1]. The World Health Organization has stated that around 2 billion people in the world are overweight and obese [2]. Prevalence of obesity in childhood is rising markedly in developed countries [3].

Globally, overweight and obesity have reached epidemic proportions, and people of the Gulf Arab countries have as well affected, particularly high-income, oil producing countries. In fact, the prevalence of obesity among children and adolescents in the Gulf Countries ranges from $(5-14 \%)$ in males and from (3-18\%) in females[4]. Importantly, obese children are at higher risk of being obese as adults in the future. In obesity, numerous pathological alterations of the white adipocytes ensue[5]. Hyperplastic (cell number increase) and hypertrophic (cell size increase) growth of adipose tissues can be found with the diameters exceeding the diffusional limit of oxygen. In addition, it is assumed that "local hypoxia, cell death, and macrophage infiltration occur consequently and lead to an altered adipokine secretion profile with an upregulation of inflammatory factors", that is contribute to supporting the low-grade chronic inflammation reported in obesity[6].

Visfatin, an adipokines with proinflammatory properties that is secreted mainly by adipocytes [7]. Visfatin, is a protein with 473 amino acids and has a molecular weight of $52 \mathrm{k}-\mathrm{Da}$ [8]. More recently, attention has been drawn to the important role of various adipokines in the pathophysiology of obesity [9]. Visfatin is generally released by many cell types, for example bone marrow, muscle cells, hepatocytes and it is additionally secreted by adipocytes, and its level is connected to obesity. Visfatin is involved in the process by which preadipocytes get differentiated into adipocytes and functions as a pre-B cell colony-enhancing factor (PBEF). Furthermore, it promotes synthesis and storage 
of triglycerides in adipocytes. The production of visfatin is regulated by multiple elements, and the most essential role played by tumor necrosis factor (TNF alpha) [10], In addition, visfatin promotes the proliferation of endothelial cell, that is mediated by the cell factor production, in addition to smooth muscle cell growth [7].

Visfatin level is associated with body mass index (BMI), fasting glucose and lipid profile. In fact, the patho-mechanism of visfatin effect is not entirely clarified. At first, an insulin-like effect has been suggested because of visfatin binding to the insulin receptor; However, this mechanism has not been confirmed [11]. The increase in percentage of individuals who have obesity is no longer an issue of only the highlydeveloped countries since it is as well found in the developing countries [12]. This phenomenon may very easily be linked to economic elements as the processed food is inexpensive as well as easily available. In fact, the nutrient value of a food is frequently a secondary issue, whereas much more crucial food choice factor is the economic element [13].

In this investigation, the aim was to evaluate visfatin level in Iraqi children and adolescents with obesity, as well as to study the association of serum visfatin level with different biochemical variables in the obese children and adolescents.

\section{MATERIAL AND METHODS}

In this study, ninety obese children and adolescents were included. Participants' ages ranged between ( 5 and 18) years. Sixty obese children and adolescents (obese group) compared to thirty children and adolescents (control group). This present study was carried out between November 2019 October 2020. Participants have been selected from the outpatient department of National Diabetes Centre-Mustansiriyah University. The whole procedure has been explained to all subjects. Approval from the ethics committee has been obtained. At first, (5) ml of morning blood has been collected from all the participants by using disposable plastic syringes. Then the needle has been removed from the syringe and the blood has been transferred into the test tubes and has been allowed to clot. After that the test tube has been centrifuged. Eventually, the separated serum has been collected into labeled microcentrifuge tubes and have been stored in ultrafreezer at $\left(-40 C^{0}\right)$ until the analysis. General and demographic characteristics: age, sex, weight, height, BMI, hip circumference, waist circumference and waist-hip ratio (WHR) of all participants have been noted. The Body fat percentage $(\mathrm{BF} \%)$ of the participants have been determined using the Equation: $\mathrm{BF} \%=(1.51 \times \mathrm{BMI})-(0.7 \times$ Age $)-$ $(3.6 \times$ Gender $)+1.4$

Gender $($ males $=1$, females $=0$ ) [14]. Serum concentrations of: fasting blood sugar (FBS), post prandial blood sugar (PPBS) and lipid profile (total cholesterol (TC), triglyceride (TG), high-density and low-density lipoproteins cholesterol (HDL-C) and (LDLC)) have been determined by using automated analyser. Serum insulin concentrations have been determined by the DRG ELISA kit [15]. Homeostasis model for insulin resistance (HOMA-IR) have been estimated by: HOMA$\mathrm{IR}=$ fasting insulinemia $(\mathrm{mU} / \mathrm{L}) \mathrm{x}$ fasting glycemia $(\mathrm{mmol} / \mathrm{L}) / 22.5$ [16]. Serum visfatin concentrations have been measured by the (CUSABIO) ELISA kit. Statistical significance was analyzed through the use of SPSS. All data are expressed as the means \pm SD or $\mathrm{n}(\%)$ and all tested of $\mathrm{P}$-values $\leq 0.05$ have been considered statistically significant.

\section{RESULTS}

General information and biochemical values of obese group and control group were summarized in table 1 . Weight, BMI, waist, FBS, insulin, HOMA-IR, TC, BF\% and LDL-C were significantly increased $(\mathrm{P}<0.05)$ in obese group compare to control group. In addition, there was a highly significant increase $(\mathrm{P}<0.01)$ in serum $\mathrm{TG}$ and visfatin levels in obese group in comparison with control group. Figure 1 shows the comparison of serum visfatin concentration between males and females in obese group.

Table 2 shows the comparison between obese children and obese adolescents. There was a significant increase $(\mathrm{P}<0.05)$ in weight, height, waist circumference, $\mathrm{TG}$, and LDL-C in obese adolescents in comparison with obese children. Furthermore, there was a highly significant increas $(\mathrm{P}<0.01)$ in serum visfatin level in obese adolescents in comparison with obese children.

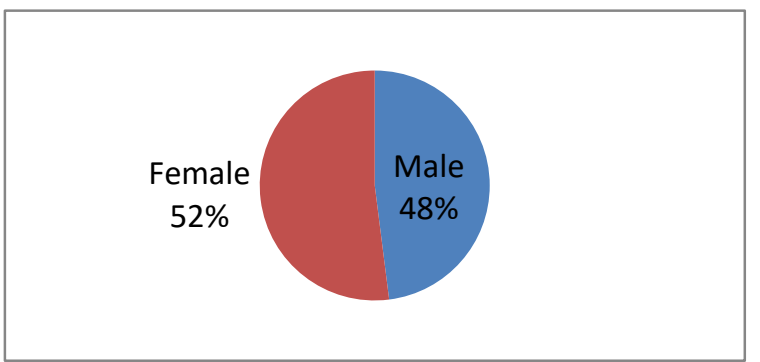

Figure 1 Comparison of serum visfatin concentration between males and females in obese group.

Table 3 displays a significant positive association between serum visfatin level verse weight, waist circumference, HOMA-IR and LDL-C in both obese children and obese adolescents, $(\mathrm{P}<0.05)$. Furthermore, a positive association was detected between serum visfatin level verses FBS and TG in both obese children and obese adolescents, $(\mathrm{P}<0.0)$ 
Table 1. General information and biochemical values

\begin{tabular}{|c|c|c|c|}
\hline Parameters & $\begin{array}{l}\text { Obese } \\
\text { No(60) } \\
\text { Mean士SD }\end{array}$ & $\begin{array}{l}\text { Control } \\
\text { No(30) } \\
\text { Mean士SD }\end{array}$ & $\mathrm{p}$-value \\
\hline $\operatorname{Sex}(M / F)$ & $(27 / 33)$ & $(14 / 16)$ & I \\
\hline Age(years) & $11.44 \pm 2.05$ & $10.15 \pm 3.81$ & 0.32 \\
\hline Hight $(\mathrm{cm})$ & $124.25 \pm 13.28$ & $123.13 \pm 12.75$ & 0.36 \\
\hline Weight(kg) & $69.62 \pm 5.31$ & $45.90 \pm 4.61$ & $0.05^{*}$ \\
\hline $\operatorname{BMI}\left(\mathrm{Kg} / \mathrm{m}^{2}\right)$ & $31.1 \pm 6.02$ & $23.12 \pm 2.31$ & $0.05^{*}$ \\
\hline $\mathrm{Hip}(\mathrm{cm})$ & $104.88 \pm 7.36$ & $101.05 \pm 3.59$ & 0.65 \\
\hline Waist(cm) & $102.58 \pm 7.3$ & $86.33 \pm 4.81$ & $0.05^{*}$ \\
\hline WHR & $0.97 \pm 0.59$ & $0.850 \pm 0.7$ & 0.16 \\
\hline FBS (mg/dl) & $103.22 \pm 4.52$ & $77.45 \pm 4.77$ & $0.05^{*}$ \\
\hline PPBS (mg/dl) & $139.22 \pm 6.36$ & $115.33 \pm 5.61$ & 0.15 \\
\hline Insulin level $(\mu \mathrm{U} / \mathrm{ml})$ & $18.46 \pm 5.47$ & $12.53 \pm 5.61$ & $0.05^{*}$ \\
\hline HOMA-IR & $3.93 \pm 1.37$ & $1.20 \pm 0.67$ & $0.05^{*}$ \\
\hline $\mathrm{TC}(\mathrm{mg} / \mathrm{dl})$ & $189.08 \pm 12.9$ & $154.44 \pm 13.22$ & $0.05^{*}$ \\
\hline $\mathrm{TG}(\mathrm{mg} / \mathrm{dl})$ & $185.06 \pm 6.84$ & $95.63 \pm 9.74$ & $0.01^{* *}$ \\
\hline HDL-c(mg/dl) & $41.64 \pm 3.79$ & $52.50 \pm 5.46$ & 0.74 \\
\hline LDL-c(mg/dl) & $123.42 \pm 13.01$ & $83.23 \pm 10.26$ & $0.05^{*}$ \\
\hline $\mathrm{BF} \%$ & $22.11 \pm 2.30$ & $15.21 \pm 7.56$ & $0.05^{*}$ \\
\hline Visfatin (ng/ml) & $26.49 \pm 4.70$ & $12.53 \pm 5.61$ & $0.01^{* *}$ \\
\hline \multicolumn{4}{|c|}{ Levels of significance: ${ }^{*} \mathrm{P}<0.05$ and ${ }^{* *} \mathrm{P}<0.01$. } \\
\hline
\end{tabular}

Table 2. Comparison of the biochemical parameters between obese children and obese adolescents

\begin{tabular}{|c|c|c|c|}
\hline Parameters & $\begin{array}{l}\text { Obese children } \\
\text { No(30) }\end{array}$ & $\begin{array}{l}\text { Obese adolescents } \\
\text { No(30) }\end{array}$ & $p$-value \\
\hline & Mean $\pm S D$ & Mean $\pm S D$ & \\
\hline $\operatorname{Sex}(M / F)$ & $(17 / 13)$ & $(15 / 15)$ & 1 \\
\hline Age(years) & $9.32 \pm 2.30$ & $13.52 \pm 2.64$ & 0.16 \\
\hline Hight $(\mathrm{cm})$ & $135.7 \pm 6.50$ & $156.5 \pm 9.30$ & $0.05^{\star}$ \\
\hline Weight(kg) & $62.7 \pm 6.20$ & $97.6 \pm 8.11$ & $0.05^{*}$ \\
\hline $\mathrm{BMI}\left(\mathrm{Kg} / \mathrm{m}^{2}\right)$ & $25.10 \pm 4.42$ & $27.74 \pm 5.50$ & 0.32 \\
\hline $\mathrm{Hip}(\mathrm{cm})$ & $70.5 \pm 4.30$ & $79.61 \pm 4.23$ & 0.33 \\
\hline Waist(cm) & $91.5 \pm 4.30$ & $102.61 \pm 3.23$ & $0.04^{*}$ \\
\hline WHR & $0.64 \pm 0.02$ & $0.62 \pm 0.01$ & 0.72 \\
\hline FBS(mg/dl) & $129.02 \pm 0.50$ & $149.0 \pm 0.50$ & 0.54 \\
\hline PPBS(mg/dl) & $97.46 \pm 0.50$ & $104.0 \pm 2.74$ & 0.61 \\
\hline Insulin level $(\mu \mathrm{U} / \mathrm{ml})$ & $15.31 \pm 2.75$ & $19.0 \pm 1.72$ & 0.34 \\
\hline HOMA-IR & $3.54 \pm 1.30$ & $3.67 \pm 1.45$ & 0.63 \\
\hline $\mathrm{TC}(\mathrm{mg} / \mathrm{dl})$ & $175.86 \pm 5.60$ & $180.31 \pm 0.50$ & 0.06 \\
\hline $\mathrm{TG}(\mathrm{mg} / \mathrm{dl})$ & $159.60 \pm 6.80$ & $187.11 \pm 8.14$ & $0.05^{*}$ \\
\hline $\mathrm{HDL}-\mathrm{C}(\mathrm{mg} / \mathrm{dl})$ & $50.17 \pm 5.40$ & $57.11 \pm 6.71$ & 0.31 \\
\hline LDL-C(mg/dl) & $103.0 \pm 6.81$ & $119.0 \pm 15.0$ & $0.05^{\star}$ \\
\hline $\mathrm{BF} \%$ & $20.11 \pm 3.39$ & $24.23 \pm 4.51$ & 0.35 \\
\hline Visfatin levels(ng/ml) & $15.5 \pm 3.21$ & $21.16 \pm 3.90$ & $0.01^{*}$ \\
\hline
\end{tabular}


Table 3. Correlations of Visfatin and different biochemical variables in obese children and obese adolescents

\begin{tabular}{|c|c|c|}
\hline \multirow[t]{2}{*}{ Parameters } & \multicolumn{2}{|c|}{ Visfatin levels } \\
\hline & $\begin{array}{l}\text { Obese children } \\
(r)\end{array}$ & $\begin{array}{l}\text { Obese Adolescents } \\
(\mathrm{r})\end{array}$ \\
\hline Age(years) & 0.201 & 0.148 \\
\hline Hight $(\mathrm{cm})$ & -0.219 & 0.728 \\
\hline Weight(kg) & $0.304^{*}$ & $0.432^{*}$ \\
\hline $\mathrm{BMI}\left(\mathrm{Kg} / \mathrm{m}^{2}\right)$ & 0.822 & 0.619 \\
\hline $\mathrm{Hip}(\mathrm{cm})$ & 0.287 & 0.608 \\
\hline Waist(cm) & $0.320^{*}$ & $0.368^{*}$ \\
\hline WHR & 0.592 & 0.502 \\
\hline FBS(mg/dl) & $0.781^{\star \star}$ & $0.732^{*}$ \\
\hline PPBS(mg/dl) & 0.761 & 0.632 \\
\hline Insulin level $(\mu \mathrm{U} / \mathrm{ml})$ & 0.102 & 0.148 \\
\hline HOMA-IR & $0.336^{*}$ & $0.355^{\star}$ \\
\hline $\mathrm{TC}(\mathrm{mg} / \mathrm{dl})$ & $0.302^{*}$ & $0.321^{*}$ \\
\hline $\mathrm{TG}(\mathrm{mg} / \mathrm{dl})$ & $0.531^{* *}$ & $0.599^{* *}$ \\
\hline $\mathrm{HDL}-\mathrm{C}(\mathrm{mg} / \mathrm{dl})$ & 0.148 & 0.219 \\
\hline LDL-C(mg/dl) & $0.351^{*}$ & $0.412^{*}$ \\
\hline $\mathrm{BF} \%$ & 0.141 & 0.133 \\
\hline & ${ }^{*} \mathrm{P}<0.05$ and ${ }^{\star \star}$ & \\
\hline
\end{tabular}

\section{DISCUSSION}

Obesity is defined simply as having excess body fat [14]. Amongst various proteins associated with obesity, visfatin has drawn a lot of attention [15]; nonetheless, the precise mechanism of its role in the pathogenesis of obesity remains unclear.

The present study showed that, serum visfatin level was highly significantly increased in the obese group in compare to control group. These results confirm previous studies [15] [16] [17] [18]. The present study revealed that serum levels of visfatin were positively related with weight in adolescents with obesity but were not associated with BMI. These results confirm the previous study of Mahaweerawat et al. [19]. Similar to the findings of this current study, Anwar et al. [18], also reported a positive association between visfatin and both weight and waist circumference in obese children and obese adolescents' groups.

This present study revealed that there was a highly significant increase in serum visfatin level in obese adolescents in comparison with obese children. Visfatin preferentially produced in the visceral adipose tissue, and it may as well be found in bone marrow, liver, skeletal muscles as well as lymphocytes, wherein it was originally identified as PBEF [20]. Indeed, the accumulation of adipocytes is because of, at least the visfatin involvement in the pathogenesis of obesity [19]. Hence, obesity of adolescents results from physical inactivity and increasing caloric intake, moreover, obesity is linked to 4 factors: cortisol, physical activity, caloric intake and somatotropin (the growth hormone). Indeed, Bouhours et al. [21] found that the children with obesity usually exhibit increased linear growth. More importantly, obesity is mainly characterized by normal to high levels of insulin-like growth factor1 (IGF-1) and high levels of growth-hormone binding-protein. Additionally, obesity, as in tall stature, can indicate an increased responsiveness to growth hormone $(\mathrm{GH})$. Thus, increased the linear growth in children with obesity, can be at least partially attributed to this increase in the GH-sensitivity. Moreover, Jin and his team [3] demonstrated that there was a significantly inverse correlation between serum visfatin levels with age, that are independent of BMI and gender in their population of adolescents with obesity. A previous study was carried out in 3T3-L1 cells revealed that the other hormones, for example, GH, Interleukin-6, dexamethasone, and TNF-alfa can affect visfatin expression [22]. They presumed that specific hormones that abnormally altered with age in adolescents with obesity, for instance $\mathrm{GH}$, estrogen, androgen, etc., might influence secretion of visfatin[22].

Nourbakhsh et al. [16] demonstrated that serum levels of visfatin showed a positive relationships with FBS and HOMA-IR in obese children and obese adolescents groups. Similarly, this present study revealed positive correlations between visfatin and FBS in addition to HOMA-IR in both obese children and obese adolescents' groups. In contrast to previous findings obtained in obese children, a study by Simões et al. [23] has shown visfatin negatively associated with HOMA-IR but this current study showed positive correlation between these two variables. The association between circulating visfatin and the parameters of glucose homeostasis and insulin resistance remains controversial due to contradicting data [24] [25] potentially due to the differences in immunoassay specificity [26].

It was reported that polymorphisms in visfatin gene were linked with TC and TG levels [27], that might suggest visfatin has an important role in lipid homeostasis. This present study found that serum levels 
of TC, TG and LDL-c were elevated in the obese group compared to those in control. Whereas no marked differences were observed in serum levels of HDL-c between these two groups. Moreover, positive correlations were detected between visfatin levels with TC, TG and LDL in both obese children and obese adolescents' groups. Against our results, Davutoglu et al. [24] and Haider et al. [25] reported that none of these lipid parameters (TG,TC, LDL-C, HDL-C, and VLDLC) were correlated with visfatin. Nonetheless, Jin et al. reported a significant correlation between visfatin and HDL-C [3]. Ethnic and racial differences could be fundamentally important for this issue.

\section{CONCLUSION}

In conclusion, serum levels of visfatin are elevated in obese group, and are also elevated in obese adolescents in comparison with obese children. Visfatin levels in both groups of obese children and obese adolescents show a significant positive correlation with weight, waist circumference, FBS, insulin resistance, LDL-C and TG. These findings suggest that visfatin may possibly play a role in the pathophysiology of obesity in children, who are at risk for a broad range of future diseases, such as type II diabetes and heart disease. However, further investigation is necessary to explore the role of adiposity, glucose and lipid metabolism to the circulating levels of visfatin in obese subjects.

\section{AUTHORS' CONTRIBUTIONS}

All authors contributed to: design and implementation of study, analysis and interpretation of data and writing of manuscript.

\section{ACKNOWLEDGMENTS}

The authors would like to thank Mustansiriyah University (www.uomustansiriyah.edu.iq) Baghdad-Iraq for its support in this study.

\section{REFERENCES}

[1] R. A. Y. Alkhader, K. A. W. Ali, and A. M. R. AlKharasani, Betatrophin: It's impact on lipid profile in type two Iraqi obese diabetic women, Indian J. Public Heal. Res. Dev., 10(4), 2019, pp. 236-241 . DOI: $10.5958 / 0976-5506.2019 .00696 . X$

[2] M. J. Alzahrani, I. Nasser, H. S. Alaamri, and W. A. Alaseeri, Serum Ghrelin Levels in Saudi Obese Asthmatic School-Children - Correlation with Interleukin-4, 2020.

[3] H. Jin, B. Jiang, J. Tang, W. Lu, W. Wang, L. Zhou, W. Shang, F. Li, Q. Ma, Y. Yang, and M. Chen, Serum visfatin concentrations in obese adolescents and its correlation with age and high-density lipoprotein cholesterol, Diabetes Res. Clin. Pract.,
79(3), 2008, pp. 412-418 . DOI: 10.1016/j.diabres.2007.09.019.

[4] S. Alnohair, Obesity in Gulf Countries, Int. J. Health Sci. (Qassim)., 8(1), 2014, pp. 79-83 . DOI: $10.12816 / 0006074$.

[5] A. Khan, N. Choudhury, S. Uddin, L. Hossain, and L. A. Baur, Longitudinal trends in global obesity research and collaboration: A review using bibliometric metadata, Obes. Rev., 17(4), 2016, pp. 377-385 . DOI: 10.1111/obr.12372.

[6] P. Fischer-Posovszky, J. Roos, P. Kotnik, T. Battelino, E. Inzaghi, V. Nobili, S. Cianfarani, M. Wabitsch, Functional Significance and Predictive Value of MicroRNAs in Pediatric Obesity: Tiny Molecules with Huge Impact?, Horm. Res. Paediatr., 86(1), 2016, pp. 3-10 . DOI: $10.1159 / 000444677$

[7] H. F. Hetta, M. E. Ez-Eldeen, G. A. Mohamed, M. A. Gaber, H. M. ElBadre, E. A. Ahmed, and M. Ahmad, Visfatin Serum Levels in Obese Type 2 Diabetic Patients: Relation to Proinflammatory Cytokines and Insulin Resistance, Egypt. J. Immunol., 25(2), 2018, pp. 141-151 .

[8] F. Carbone L. Liberale, A. Bonaventura, A. Vecchiè, M. Casula, M. Cea, and A. Nencioni, Regulation and function of extracellular nicotinamide phosphoribosyltransferase/visfatin, Compr. Physiol., 7(2), 2017, pp. 603-621 . DOI: 10.1002/cphy.c160029.

[9] K. M. Chyl-Surdacka, J. Bartosińska, M. Kowal, J. Przepiórka-Kosińska, D. Krasowska, and G. Chodorowska, Assessment of visfatin concentrations in the serum of male psoriatic patients in relation to metabolic abnormalities, Adv. Clin. Exp. Med., 29(1), 2020, pp. 79-84 . DOI: 10.17219/acem/111820.

[10] M. Jurdana, A. Petelin, M. Š. černelič Bizjak, M. Bizjak, G. Biolo, and Z. Jenko-PraŽnikar, Increased serum visfatin levels in obesity and its association with anthropometric/biochemical parameters, physical inactivity and nutrition, ESPEN. J., 8(2), 2013, pp. 59-67 . DOI: 10.1016/j.clnme.2013.02.001.

[11] M. C. Tilinca, E. C. Barabas-Hajdu, G. T. Ferencz, and E. Nemes-Nagy, Involvement of inflammatory cytokines in obesity and its complications, Rev. Rom. Med. Lab., 26(3), 2018, pp. 359-372 . DOI: 10.2478/rrlm-2018-0019.

[12] A. Spinelli M. Buoncristiano, V. A. Kovacs, A. Yngve, I. Spiroski, G. Obreja, and J. Breda, Prevalence of severe obesity among primary school 
children in 21 European countries, Obes. Facts, 12(2), 2019, pp. 244-258 . DOI: $10.1159 / 000500436$.

[13] K. Zorena, O. Jachimowicz-Duda, D. Ślęzak, M. Robakowska, and M. Mrugacz, Adipokines and obesity. Potential link to metabolic disorders and chronic complications, Int. J. Mol. Sci., 21(10), 2020, p.p. 1-18 . DOI: 10.3390/ijms21103570.

[14] R. A. Y. Alkhader, K. A. Wahab Ali, and A. M. Rahmah Al-Kharasani, Irisin levels related to glycosylated hemoglobin in type 2 diabetic obese women, Iraqi J. Sci., 61(9), 2020, pp. 2150-2155 . DOI: $10.24996 / \mathrm{ijs} .2020 .61 .9 .1$.

[15] S. Ezzati-Mobaser Z. Malekpour-Dehkordi, M. Nourbakhsh, M. Tavakoli-Yaraki, F. Ahmadpour, P. Golpour, and M. Nourbakhsh, The up-regulation of markers of adipose tissue fibrosis by visfatin in pre-adipocytes as well as obese children and adolescents, Cytokine, 134, 155193, 2020. DOI: $10.1016 /$ j.cyto.2020.155193.

[16] M. Nourbakhsh, M. Nourbakhsh, Z. Gholinejad, and M. Razzaghy-Azar, Visfatin in obese children and adolescents and its association with insulin resistance and metabolic syndrome, Scand. J. Clin. Lab. Invest., 75(2), 2015, pp. 183-188 . DOI: $10.3109 / 00365513.2014 .1003594$.

[17] A. Jaleel B. Aheed, S. Jaleel, R. Majeed, A. Zuberi, S. Khan, and H. Hashim, Association of adipokines with obesity in children and adolescents, Biomark. Med., 7(5), 2013, pp. 731-735 . DOI: 10.2217/bmm.13.41.

[18] G. M. Anwar A. A. Motawei, A. Ibrahim, A. Galal, H. M. Salama, A. A. Aly, and E. A. Moustafa, Serum visfatin level in obese Egyptian children and adolescents and its relation with metabolic syndrome, Med. Res. J., 14(2), 2015, pp. 53-58 . DOI: 10.1097/01.mjx.0000472995.93483.08.

[19] S. Mahaweerawat, U., Somdee, T., Sungkamanee, S., and Yangyuen, Serum Visfatin Concentration and Biochemistry Parameter Relationship of Obese Adolescents in Thailand, Asia-Pacific Journal of Science and Technology, 15(3), 2010, pp. 155-161, [Online]. Available: https://so01.tcithaijo.org/index.php/APST/article/view/83150.

[20] J. K. Sethi and A. Vidal-Puig, Visfatin: The missing link between intra-abdominal obesity and diabetes?, Trends Mol. Med., 11(8), 2005, pp. 344-347 . DOI: 10.1016/j.molmed.2005.06.010.

[21] N. Bouhours-Nouet, F. Gatelais, F. B. De Casson, S. Rouleau, and R. Coutant, The insulin-like growth factor-I response to growth hormone is increased in prepubertal children with obesity and tall stature, J. Clin. Endocrinol. Metab., 92(2), 2007, pp. 629-635 . DOI: $10.1210 /$ jc.2005-2631.

[22] S. Kralisch J. Klein, U. Lossner, M. Bluher, R. Paschke, M. Stumvoll, and M. Fasshauer, Hormonal regulation of the novel adipocytokine visfatin in 3T3-L1 adipocytes, J. Endocrinol., 185(3), 2005, pp. 1-8 . DOI: $10.1677 /$ joe.1.06211.

[23] N. F. Simões A. L. G. Domingos, F. L. P. De Oliveira, I. S. Caldas, M. R. Guedes, V. C. Fajardo, and S. N. De Freitas, Resistin and visfatin concentrations are related to central obesity and inflammation in Brazilian children, Nutrire, 43(1), 2018, pp. 1-8 . DOI: 10.1186/s41110-018-0060-7.

[24] M. Davutoglu M. Ozkaya, E. Guler, M. Garipardic, H. Gursoy, H. Karabiber, and M. Kilinc, Plasma visfatin concentrations in childhood obesity: Relationships to insulin resistance and anthropometric indices, Swiss Med. Wkly., 139(0102), 2009, pp. 22-27 . DOI: smw-12400.

[25] D. G. Haider G. Holzer, G. Schaller, D. Weghuber, K. Widhalm, O. Wagner, and M. Wolzt, The adipokine visfatin is markedly elevated in obese children, J. Pediatr. Gastroenterol. Nutr., 43(4), 2006, pp. 548-549. DOI: 10.1097/01.mpg.0000235749.50820.b3.

[26] A. Körner, A. Garten, M. Blüher, R. Tauscher, J. Kratzsch, and W. Kiess, Molecular characteristics of serum visfatin and differential detection by immunoassays, J. Clin. Endocrinol. Metab., 92(12), 2007, pp. 4783-4791 . DOI: 10.1210/jc.2007-1304.

[27] W. X. Jian T. H. Luo, Y. Y. Gu, H. L. Zhang, S. Zheng, M. Dai, and M. Luo, The visfatin gene is associated with glucose and lipid metabolism in a Chinese population, Diabet. Med., 23(9), 2006, pp. 967-973.DOI: 10.1111/j.1464-5491.2006.01909.x. 